\title{
Modelling of size-dependent thermodynamic properties of metallic nanocrystals based on modified Gibbs-Thomson equation
}

\author{
Manauwar Ali Ansari ${ }^{1}$
}

Received: 9 February 2021 / Accepted: 15 April 2021 / Published online: 27 April 2021

(C) The Author(s) 2021

\begin{abstract}
In this paper, a new theoretical two-phase (solid-liquid) type model of melting temperature has developed based on the modified Gibbs-Thomson equation. Further, it is extended to derive other different size-dependent thermodynamic properties such as cohesive energy, Debye temperature, specific heat capacity, the thermal and electrical conductivity of metallic nanoparticles. Quantitative calculation of the effect of size on thermodynamic properties resulted in, varying linearly with the inverse of characteristic length of nanomaterials. The models are applied to $\mathrm{Al}, \mathrm{Pb}, \mathrm{Ag}, \mathrm{Sn}, \mathrm{Mo}, \mathrm{W}, \mathrm{Co}, \mathrm{Au}$ and $\mathrm{Cu}$ nanoparticles of spherical shape. The melting temperature, Debye temperature, thermal and electrical conductivity are found to decrease with the decrease in particle size, whereas the cohesive energy and specific heat capacity are increased with the decrease in particle size. The present model is also compared with previous models and found consistent. The results obtained with this model validated with experimental and simulation results from several sources that show similar trends between the model and experimental results.
\end{abstract}

Manauwar Ali Ansari

maansarivce@gmail.com

1 Department of Material Science and Engineering, University

of Miskolc, Miskolc-Egyetemvaros 3515, Hungary 


\section{Graphic abstract}

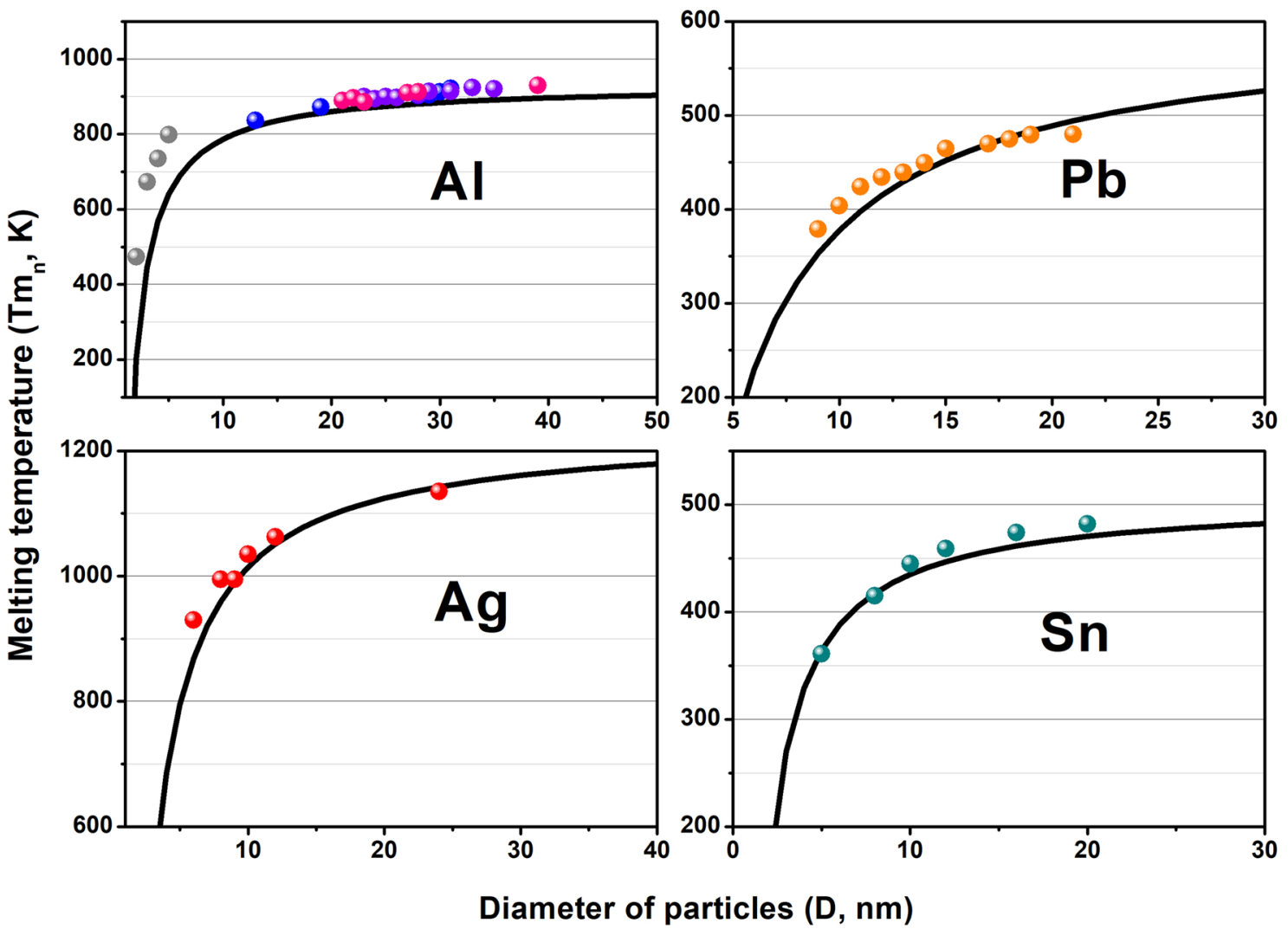

Keywords Size dependence $\cdot$ Thermodynamic properties $\cdot$ Nanocrystals $\cdot$ Gibbs-Thomson equation

\section{Introduction}

The size of the crystal plays a major role in nanoscience and nanotechnology. By definition, a material having a size of less than $100 \mathrm{~nm}$ is known as nanomaterial [1,2]. The crystal of these sizes contains as few as thousands of atoms and having remarkable and valuable characteristics. The size and shape-dependent chemo-physical characteristics of nanomaterials enabling them broadly useful in different application areas [3-9]. Nanomaterials have a large specific surface area, and the surface effect is significant which is generally insignificant for bulk materials [10].

The classical thermodynamics for the bulk material is not completely valid for nanomaterials. Further, for designing a material system based on nanomaterials, a good understanding of fundamental thermodynamic properties is required. These basic thermodynamic properties include melting temperature, boiling temperature, cohesive energy, enthalpy and entropy of melting, elastic moduli, specific heat capacity, etc. Good knowledge of these thermodynamic properties enables us to utilize them for further new applications.
In the last decade, there have been significant theoretical and experimental studies in the study of the specific properties of nanomaterials and many promising results have been obtained [11-14]. In addition, the invention of quantum theory helps us to measure the thermodynamic properties using supercomputers $[15,16]$. However, there is still a requirement to understand and develop the thermodynamic properties of nanomaterials by semi-empirical methods, which are broadly useful in materials research.

Hitherto, various size dependence melting temperature analytical models have been reported, can be categorized as either one-phase [17-28] or two-phase type [29-36]. The one-phase models fail to account for the discontinuous, firstorder character of the melting transition, as we do not know anything about solid to liquid states because it involves characteristics of only one of the two phases coexisting at melting, i.e. the solid-phase alone, with no separate description of the liquid-phase. However, two-phase models consider both phases, solid as well as the liquid phases [37].

Kaptay G. (2012) modified the Gibbs-Thomson equation (previously based on Kelvin equation) and clearly 
stated that the difference in the behaviour of nano-system compared to macro-system is due to their high specific surface area (due to Gibbs) and not to the high curvature of their interface (due to Kelvin). This equation (melting temperature of nanocrystals) gives us a new insight to look into other size-dependent thermodynamic properties by giving new material parameters (thermodynamic) in all the equations for size-dependent properties [38, 39].

In the present work, a new analytical model of melting temperature has been developed based on the modified Gibbs-Thomson equation and compared with both type one-phase and two-phase model to confirm the consistency of the previous trends. Further, it is extended to derive other different size-dependent thermodynamic properties such as cohesive energy, melting temperature, Debye temperature and specific heat capacity, the thermal and electrical conductivity of metallic nanoparticles. The present model predictions are compared with several sources including both experimental and theoretical results.

\section{Results and discussion}

\subsection{Melting temperature}

The dependence of melting temperature on the size of nanomaterials has been already proven both experimentally as well as theoretically $[11,12,25,40-46]$. Depression of the melting temperature exists for almost all free nanoparticles [40-42]. Thermodynamic models were revised to understand how free nanoparticles melt and overheat $[11,12,25$, 46]. Kaptay G. (2012) reported the modified Gibbs-Thomson equation for size dependence of melting temperature of nanocrystals. The modified Gibbs-Thomson equation analogue with Gibbs (not Kelvin) the size-dependent of the melting temperature of metallic nanocrystals can be derived [38].

Let us consider a pure metallic solid situated in a large liquid of the same composition. From the general condition of equilibrium between one component of solid and its liquid

$G_{m, s}^{\circ}=G_{m, l}^{\circ}$

where $G_{m, \Phi}^{\circ}$ term is used for molar standard Gibbs free energy for phases $(\Phi=\mathrm{s}$ (solid) and $\Phi=1$ (liquid)).

Writing Gibbs free energy in terms of molar standard enthalpy and entropy,

$H_{m,(s)}^{\circ}-T_{m} S_{m,(s)}^{\circ}=H_{m,(l)}^{\circ}-T_{m} S_{m,(l)}^{\circ}$

or

$T_{m} \Delta_{m} S_{m}^{\circ}=\Delta_{m} H_{m}^{\circ}$ or melting temperature for the bulk metal phase,

$T_{m_{b}}=\frac{\Delta_{m} H_{m}^{\circ}}{\Delta_{m} S_{m}^{\circ}}$

Now, for nanophase, the melt equilibrium can be written as,

$G_{m, s}^{\circ}+A_{s p, s} V_{m, s} \gamma_{s g}=G_{m, l}^{\circ}+A_{s p, l} V_{m, l} \gamma_{l g}$

This extra energy is due to high surface area of nanocrystals, where $\mathrm{A}_{\mathrm{sp}, \Phi} \mathrm{V}_{\mathrm{m}, \Phi}$ are specific area and molar volume for phases $\left(\Phi=\mathrm{s}\right.$ (solid) and $\Phi=1$ (liquid)) and $\gamma_{\mathrm{sg}}$ and $\gamma_{\mathrm{lg}}$ are surface energy of solid and surface tension of liquid, respectively,

$H_{m,(s)}^{\circ}-T_{m_{n}} S_{m,(s)}^{\circ}+A_{s p, s} V_{m, s} \gamma_{s g}=H_{m,(l)}^{\circ}-T_{m_{n}} S_{m,(l)}^{\circ}+A_{s p, l} V_{m, l} \gamma_{l g}$

$$
\text { If. } A_{s p, s}=A_{s p, l}=A_{s p} \text { and } V_{m, s}=V_{m, l}=V_{m}
$$

$T_{m n}=\left(\frac{\Delta_{m} H_{m}^{\circ}}{\Delta_{m} S_{m}^{\circ}}-\frac{A_{s p .} V_{m}\left(\gamma_{s g}-\gamma_{l g}\right)}{\Delta_{m} S_{m}^{\circ}}\right)$

By using equation (4)

$T_{m n}=\left(T_{m b}-\frac{A_{s p .} V_{m}\left(\gamma_{s g}-\gamma_{l g}\right)}{\Delta_{m} S_{m}^{\circ}}\right)$

or

$T_{m n}=T_{m b}\left(1-\frac{A_{s p .} V_{m}\left(\gamma_{s g}-\gamma_{l g}\right)}{\Delta_{m} H_{m}^{\circ}}\right)$

For spherical nanoparticles sp. surface area $A_{s p .}$ is $6 / \mathrm{D}$, where $\mathrm{D}$ is the diameter of particles.

$T_{m n(\text { sphere })}=T_{m b}\left(1-\frac{6 V_{m}\left(\gamma_{s g}-\gamma_{l g}\right)}{D \Delta_{m} H_{m}^{\circ}}\right)$

It is clear from Eq. (8) that the approach to determining $T_{m n}$ is to obtain the expression $\frac{A_{s p} V_{m}\left(\gamma_{s g}-\gamma_{l g}\right)}{\Delta_{m} H_{m}^{\circ}}$, which depends not only on nanocrystals size but also on the shape because the specific surface area is different for different-shaped crystals. Further, for spherical nanoparticles, obtained Eq. (9) is found in accord with most of the thermodynamic models, the melting temperature changes linearly with the reciprocal of particle size. In other words, the melting temperature of nanomaterials changes linearly with $1 / D$. On comparing the generalized model for melting temperature reported by Qi WH [24], we found new material parameter $\left(\frac{A_{s p} V_{m}\left(\gamma_{s g}-\gamma_{l g}\right)}{\Delta_{m} H_{m}^{\circ}}\right)$ in spite of N/2n.

Figure 1 is the dependence of melting temperature on the size of spherical $\mathrm{Al}, \mathrm{Pb}, \mathrm{Ag}$ and $\mathrm{Sn}$ nanoparticles in terms 


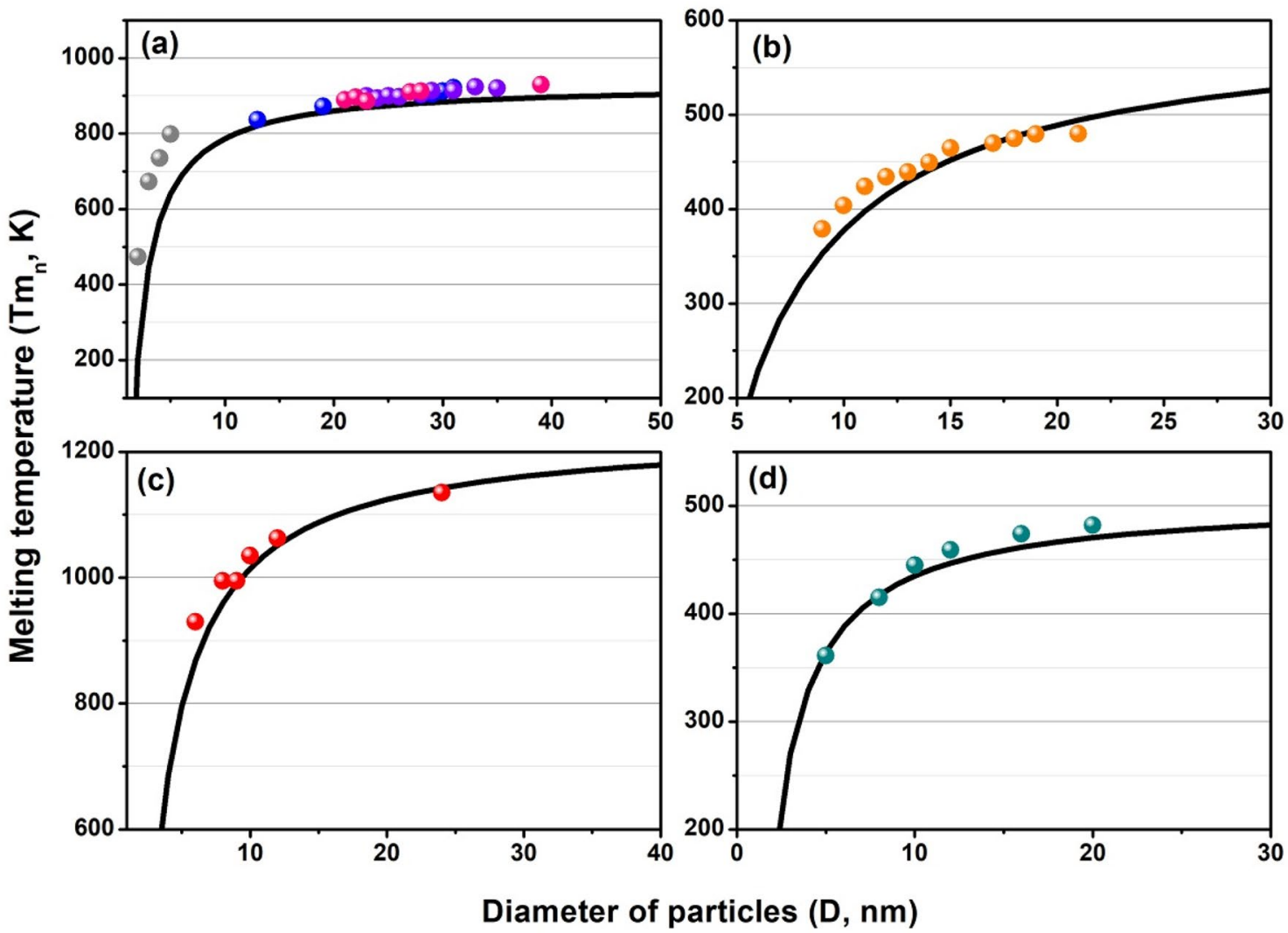

Fig. 1 Dependence of melting temperature on the size of spherical metallic nanoparticles in terms of Eq. (9). a for $\mathrm{Al}$, simulation results (grey sphere) [42], experimental results represented by blue sphere $(\mathrm{Al} / \mathrm{O})$, violet sphere $(\mathrm{Al} / \mathrm{H})$ and pink sphere $(\mathrm{Al} / \mathrm{Ar})$ [48]. b for $\mathrm{Pb}$

of Eq. (9). From Fig. 1a, b, c and d, it is clear that the present model is in a similar trend with the previously reported model based on one-phase [24] and two-phase model [22]. The decrease in the melting temperature of nanoparticles is only noticeable below $100 \mathrm{~nm}$. When the size of the particle is greater than $100 \mathrm{~nm}$, the melting temperature of the particles is about the same as the corresponding bulk crystals or we can say, the melting temperature becomes independent of the size of nanoparticles. The experimental results in Fig. 1(a) are of three forms, $\mathrm{Al} / \mathrm{H}, \mathrm{Al} / \mathrm{O}$ and $\mathrm{Al} / \mathrm{Ar}$, which are nothing but milling gas environments as hydrogen $(\mathrm{H})$, oxygen $(\mathrm{O})$ and argon $(\mathrm{Ar})$ in aluminium nanoparticles preparation, respectively. The experimental data clearly support the prediction [41, 42, 47, 48]. Melting temperature varies gradually with the variation of size, and the curves are nearly horizontal for $\mathrm{D}=80 \mathrm{~nm}$. However, on the contrary, the size effect is very distinct in the range of $\mathrm{D}=10 \mathrm{~nm}$. The melting temperature rapidly decreases with a slight reduction in particle size $y$ From equation (9), if the particle size is fairly large, i.e. $\frac{\Delta_{m} H_{m}^{\circ}}{D} \gg 1$, then $T_{m n} \approx T_{m b}$. The present model can provide accurate predictions for $\mathrm{Al}, \mathrm{Ag}$ and $\mathrm{Sn}$ nanoparticles nanoparticles experimental results (orange sphere) [47]. c for Ag nanoparticles experimental results (red sphere) [41]. d for Sn nanoparticles experimental results (dark cyan sphere) [47]. Input parameters for Eq. (9) are given in Tables 1 and 2

on the melting temperature within the full-size range, while for $\mathrm{Pb}$ nanoparticles, a little variation is noted.

\subsection{Cohesive energy}

Cohesion energy (or binding energy) is a fundamental energetic property of metals that affects most of their other physical properties. Solid and liquid metals cohesion energy is the energy binding atoms in solid and/or liquid state [49]. From the classical model, bulk cohesive energy can be given as:

$\Delta U_{s-l, T m}=\int_{0 K}^{T m} C_{p, s} d T+\Delta_{m} H$

where $C_{p, s}$ - is the isobaric heat capacity of solid,

$\Delta_{m} H$-is the enthalpy of melting of the metal at its melting point.

or [49]

$\Delta_{b} U_{s-l, T m}=C_{p, s} T_{m}+\Delta_{m} H_{m}^{\circ}$ 
Using equation (4)

$\Delta_{b} U_{s-l, T m}=C_{p, s} T_{m_{b}}+T_{m_{b}} \Delta_{m} S_{m}$

or

$\Delta_{b} U_{s-l, T m}=T_{m_{b}}\left(C_{p, s}+\Delta_{m} S_{m}\right)$

For a nanophase,

$\Delta_{n} U_{s-l, T m}=T_{m_{n}}\left(C_{p, s}+\Delta_{m} S_{m}\right)$

Using equation (8), we get

$\Delta_{n} U_{s-l, T m}=\left(C_{p, s}+\Delta_{m} S_{m}\right) T_{m_{b}}\left(1-\frac{A_{s p .} V_{m}\left(\gamma_{s g}-\gamma_{l g}\right)}{\Delta_{m} H_{m}^{\circ}}\right)$

$\Delta_{n} U_{s-l, T m}=\Delta_{b} U_{s-l, T m}\left(1-\frac{A_{s p .} V_{m}\left(\gamma_{s g}-\gamma_{l g}\right)}{\Delta_{m} H_{m}^{\circ}}\right)$

If $\Delta_{n} U_{s-l, T m}=U_{n}$ and $\Delta_{b} U_{s-l, T m}=U_{b}$, then

$U_{n}=U_{b}\left(1-\frac{A_{s p .} V_{m}\left(\gamma_{s g}-\gamma_{l g}\right)}{\Delta_{m} H_{m}^{\circ}}\right)$

For spherical nanoparticles

$U_{n}=U_{b}\left(1-\frac{6 V_{m}\left(\gamma_{s g}-\gamma_{l g}\right)}{D \Delta_{m} H_{m}^{\circ}}\right)$

The value of cohesive energy is calculated using Eq. (15) for spherical nanoparticles. Input parameters required for the calculation are given in Tables 1 and 2. The size dependence of cohesive energy for Mo and W nanoparticles is shown in Fig. 2. It is seen that the cohesive energy for both Mo and W nanoparticles decreases on increasing the particle size. The results of Eq. (15) are compared with experimental results [50]. It is noted that our model predictions are consistent in terms of trend and experimental values, with the exception of the value for $\mathrm{W}$ nanoparticles at $1 \mathrm{~nm}$ and arising from the fact that our model deals not only with the size but also the shape of nanocrystals. The current prediction for Mo nanoparticles is also compared with the results of the model reported by Qi [24, 51]. There is reasonably good agreement between theory and experiment, and present model prediction is more accurate than the one-phase model [24, 51]. This difference in the two models is because of the fact that our model is based on energy rather than the number of atoms which makes it more detailed and practical.

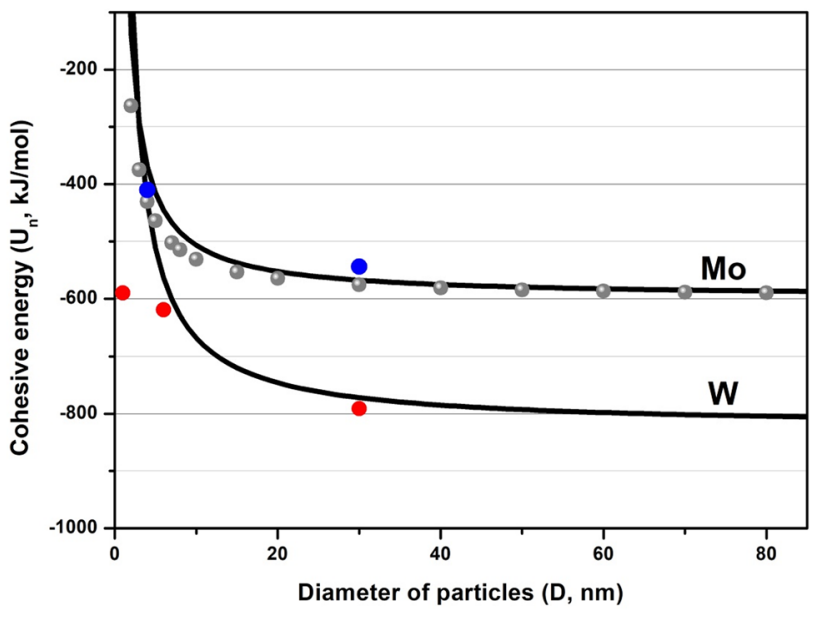

Fig. 2 Dependence of cohesive energy on the size of spherical Mo and $\mathrm{W}$ nanoparticles in terms of Eq. (15). Grey sphere shows results for Mo of model reported by Qi $[24,51]$ and solid blue and red circle represent experimental data for Mo and W, respectively [50]. The atomic radius for Mo is $162 \mathrm{pm}$ [52]. The input parameter for Mo and $\mathrm{W}$ is given in Tables 1 and 2

\subsection{Debye temperature}

The Debye temperature is directly linked to the binding force between atoms and strongly dependent on materials structure [53]. It is an essential thermodynamic property because it provides fundamental knowledge to understand other series of thermodynamic properties, such as specific heat capacity, lattice vibration [54] vibrational entropy, Helmholtz free energy [55] and thermal conductivity. According to Lindemann Criterion of melting, the relationship between melting temperature and Debye temperature of bulk metals can be defined as follows [56]:

$\theta_{D_{b}}=c\left(\frac{T_{m_{b}}}{M V^{2 / 3}}\right)^{1 / 2}$

where $\mathrm{c}$ is a constant, $\mathrm{M}$ is molecular mass, $T_{m_{b}}$ is bulk melting point, and $\mathrm{V}$ is the volume per atom. From Eq. (16), the Debye temperature for bulk is directly proportional to the square root of the melting temperature $\theta_{D_{b}} \propto T_{m_{b}}{ }^{1 / 2}$

Similarly, for a nanophase, Debye temperature can be written as,

$\theta_{D_{n}} \propto T_{m_{n}}^{1 / 2}$

or [57]

$\frac{\theta_{D_{n}}}{\theta_{D_{b}}}=\left(\frac{T_{m_{n}}}{T_{m_{b}}}\right)^{1 / 2}$

Using Eq. (8) we get, 
$\theta_{D_{n}}=\theta_{D_{b}}\left(1-\frac{A_{s p .} V_{m}\left(\gamma_{s g}-\gamma_{l g}\right)}{\Delta_{m} H_{m}^{\circ}}\right)^{1 / 2}$

For spherical NPs,

$\theta_{D_{n}}=\theta_{D_{b}}\left(1-\frac{6 V_{m}\left(\gamma_{s g}-\gamma_{l g}\right)}{D \Delta_{m} H_{m}^{\circ}}\right)^{1 / 2}$

Equation (16) reveals that the Debye temperature is in proportion to the square root of melting temperature and Eq. (19) demonstrates the size effect on the Debye temperature. Comparisons between the model result from Eq. (19) and the available experimental results for the Debye temperature of $\mathrm{Co}, \mathrm{Au}$ and $\mathrm{Sn}$ nanoparticles are shown in Fig. 3. It clearly indicates the depression of the Debye temperature of nanoparticles with particle size. Moreover, the curve is smoother than that of the melting temperature in the small size range, showing that the rate of depression with the size is smaller compared to the melting temperature. In the largediameter range approx. $(>10 \mathrm{~nm})$, the Debye temperature independent of the size and equals the bulk value.

\subsection{Thermal conductivity}

As we already mentioned in previous Sect. 2.3 that thermal conductivity is also related to Debye temperature. Thus, thermal conductivity for nanoparticles can be calculated from the size-dependent Debye temperature. According to kinetic theory equation [61], the thermal conductivity $\left(\mathrm{K}_{\mathrm{b}}\right)$ of metals (bulk) can be expressed as [61]:

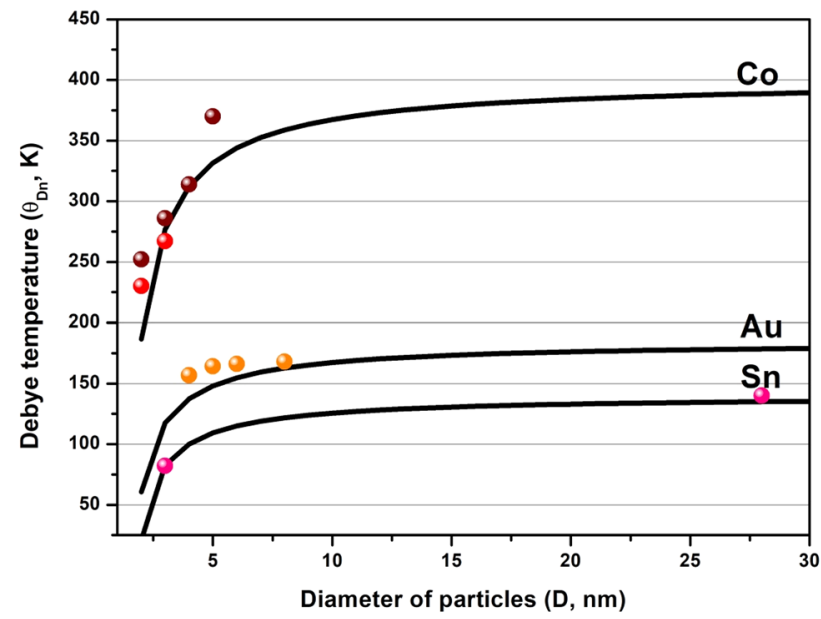

Fig. 3 Dependence of Debye temperature on the size of spherical $\mathrm{Co}, \mathrm{Au}$ and $\mathrm{Sn}$ nanoparticles in terms of Eq. (19). Wine and red solid sphere represent experimental and simulation results for Co [58], orange sphere represents experimental results for $\mathrm{Au}$ [59] and pink sphere represents experimental results for Sn [60]. Input parameters for $\mathrm{Au}$ are given in Tables 1 and 2
$K_{b}=\frac{1}{3} c v_{b} \lambda_{b}$

where $\mathrm{c}$ is the specific heat, $v_{b}$ is the average phonon velocity, and $\lambda_{b}$ is the mean free path.

$K_{b} \propto v_{b} \lambda_{b}$

Similarly, for nanophase thermal conductivity

$K_{n} \propto v_{n} \lambda_{n}$

By combining Eq. (21) and (22),

$\frac{K_{n}}{K_{b}}=\frac{v_{n} \lambda_{n}}{v_{b} \lambda_{b}}$

The relation between Debye temperature and average phonon velocity of bulk crystal [62], can be expressed as

$\theta_{D_{b}} \propto \frac{2 h}{\pi k_{B}}\left(\frac{3 N_{A}}{4 \pi V}\right)^{1 / 3} v_{b}$

$\theta_{D_{n}} \propto \frac{2 h}{\pi k_{B}}\left(\frac{3 N_{A}}{4 \pi V}\right)^{1 / 3} v_{n}$

or

$\frac{\theta_{D_{n}}}{\theta_{D_{b}}}=\frac{v_{n}}{v_{b}}$

from Eq. (17)

$\frac{\theta_{D_{n}}}{\theta_{D_{b}}}=\left(\frac{T_{m_{n}}}{T_{m_{b}}}\right)^{1 / 2}=\left(1-\frac{A_{s p .} V_{m}\left(\gamma_{s g}-\gamma_{l g}\right)}{\Delta_{m} H_{m}^{\circ}}\right)^{1 / 2}$

The relation between mean free path $(\lambda)$ and melting temperature [57] can be given as,

$\frac{\lambda_{n}}{\lambda_{b}}=\left(\frac{T_{m_{n}}}{T_{m_{b}}}\right)$

or

$\frac{K_{n}}{K_{b}}=\frac{v_{n} \lambda_{n}}{v_{b} \lambda_{b}}=\left(\frac{T_{m_{n}}}{T_{m_{b}}}\right)^{3 / 2}$

Now, using Eq. (8), we get,

$\boldsymbol{K}_{\boldsymbol{n}}=\boldsymbol{K}_{\boldsymbol{b}}\left(1-\frac{\boldsymbol{A}_{\boldsymbol{s p} .} \boldsymbol{V}_{\boldsymbol{m}}\left(\gamma_{\boldsymbol{s g}}-\gamma_{l g}\right)}{\Delta_{m} H_{m}^{\circ}}\right)^{3 / 2}$

For spherical metal nanoparticles, 


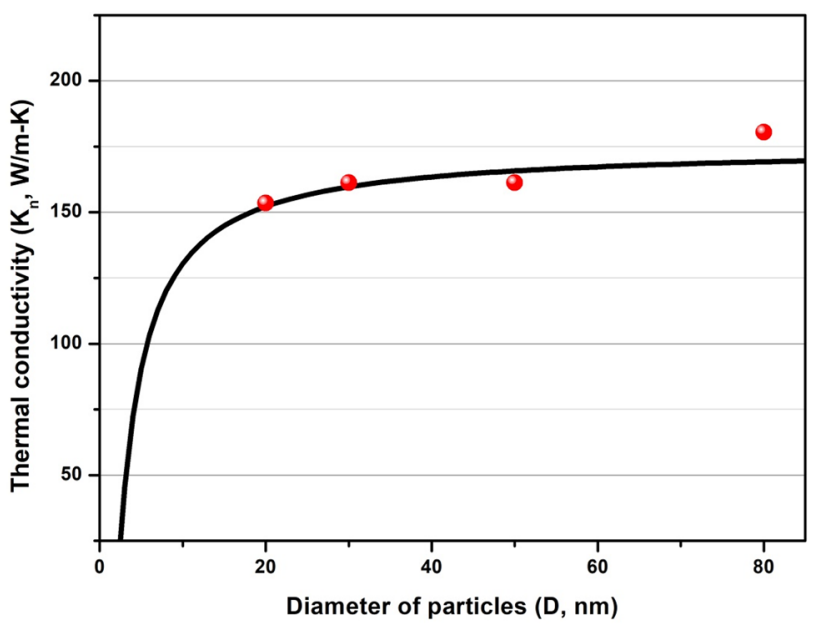

Fig. 4 Dependence of thermal conductivity on the size of spherical $\mathrm{Ag}$ nanoparticles in terms of Eq. (31) and experimental data (red sphere) [63]. The input parameter for $\mathrm{Ag}$ is given in Tables 1 and 2

$K_{n}=K_{b}\left(1-\frac{6 V_{m}\left(\gamma_{s g}-\gamma_{l g}\right)}{D \Delta_{m} H_{m}^{\circ}}\right)^{3 / 2}$

Prediction of the present model along with experimental results for $\mathrm{Ag}$ nanoparticles is shown in Fig. 4. It is found that our results are slightly varied in comparison to the results obtained by [63], but it almost agrees with experimental data.

\subsection{Electrical conductivity}

We know that thermal conductivity and electrical conductivity have a linear relationship based on the Wiedemann-Franz ratio, with $\mathrm{K} / \sigma$ is proportional to the absolute temperature $\mathrm{T}$ $[64,65]$. From this relationship, for the same temperature, electrical and thermal conductivity will be proportional. On a nanometer scale, thermal conductivity tends to decrease with decreasing size $[63,65]$.

From Wiedemann-Franz law for bulk metals at a high constant temperature $\mathrm{T}$ [65].

$\frac{K_{b}}{\sigma_{b}}=\frac{\pi^{2}}{3}\left(\frac{k_{B}}{e}\right)^{2} T$

where $\mathrm{K}_{\mathrm{b}}$ is bulk thermal conductivity $\left(\mathrm{W} / \mathrm{m}-{ }^{\circ} \mathrm{K}\right), \sigma_{\mathrm{b}}$ is bulk electrical conductivity $(\Omega-\mathrm{m})^{-1}$ and $\frac{\pi^{2}}{3}\left(\frac{k_{B}}{e}\right)^{2}=L$ is Lorentz number $\left(2.3 \times 10^{-8} \mathrm{~W}-\mathrm{ohm} /{ }^{\circ} \mathrm{K}^{2}\right)$.

$\sigma_{b} \propto K_{b}$

Similarly, for the nanophase

$\sigma_{n} \propto K_{n}$

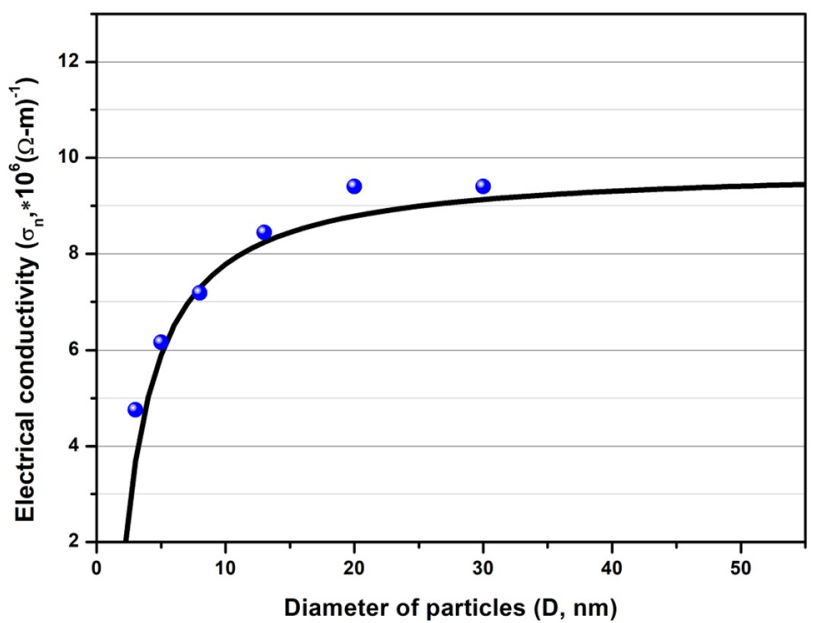

Fig. 5 Dependence of electrical conductivity on the size of spherical $\mathrm{Cu}$ nanoparticles in terms of Eq. (37) and experimental data (blue sphere) [67]. Input parameters for $\mathrm{Cu}$ are given in Tables 1 and 2

or

$\frac{\sigma_{n}}{\sigma_{b}}=\frac{K_{n}}{K_{b}}$

By using Eq. (29),

$\sigma_{n}=\sigma_{b}\left(1-\frac{A_{s p .} V_{m}\left(\gamma_{s g}-\gamma_{l g}\right)}{\Delta_{m} H_{m}^{\circ}}\right)^{3 / 2}$

For the spherical nanoparticles,

$\sigma_{n}=\sigma_{b}\left(1-\frac{6 V_{m}\left(\gamma_{s g}-\gamma_{l g}\right)}{D \Delta_{m} H_{m}^{\circ}}\right)^{3 / 2}$

Prediction of the present model (38) for $\mathrm{Cu}$ along with experimental results is shown in Fig. 5. These results were validated with experimental results from several sources such as Yuliza et al. (2015) [66] based on the kinetic theory of the electron and show similar trends between the model and experimental results.

\subsection{Specific heat capacity}

The definition of specific heat capacity of the material (solid or liquid) is the heat required to raise one degree of the temperature of a unit mass of material. In the bulk phase, the specific heat capacity only depends on the temperature, not on the size. While in the nanophase, the surface effects cause the specific heat capacity of the material to vary from the bulk. As we already mentioned in Sect. 2.3 that the specific heat capacity is also related to Debye temperature. According to Debye's theory [68], isobaric specific heat and the Debye temperature of the bulk material can be related as [69], 
$C_{P_{b}} \propto \theta_{D_{b}}^{2}$

Similarly, for a nanomaterial,

$C_{P_{n}} \propto \theta_{D_{n}}^{2}$

From Eq. (38) and (39),

$\frac{C_{P_{n}}}{C_{P_{b}}}=\frac{T_{m_{b}}}{T_{m_{n}}}$

Using Eq. (8), we get

$C_{P_{n}}=C_{P_{b}}\left(1-\frac{\boldsymbol{A}_{s p .} \boldsymbol{V}_{\boldsymbol{m}}\left(\gamma_{s g}-\gamma_{l g}\right)}{\Delta_{m} H_{m}^{\circ}}\right)^{-1}$

For spherical nanoparticles,

$C_{P_{n}}=C_{P_{b}}\left(1-\frac{6 \boldsymbol{V}_{\boldsymbol{m}}\left(\gamma_{s g}-\gamma_{l g}\right)}{D \Delta_{m} H_{m}^{\circ}}\right)^{-1}$

This is the relationship of the isobaric specific heat for nanomaterials and bulk materials at different shapes and sizes. The size dependence of isobaric specific heat capacity for Ag nanoparticles along with the results of the model [14] and experimental data [70] is plotted in Fig. 6. It is reported by Rupp et. al. [71] that the specific heat increases with decreasing size of the nanocrystal, showing the specific heat capacity varies inversely with the particle size. The main reason for the elevated specific heat at a small scale

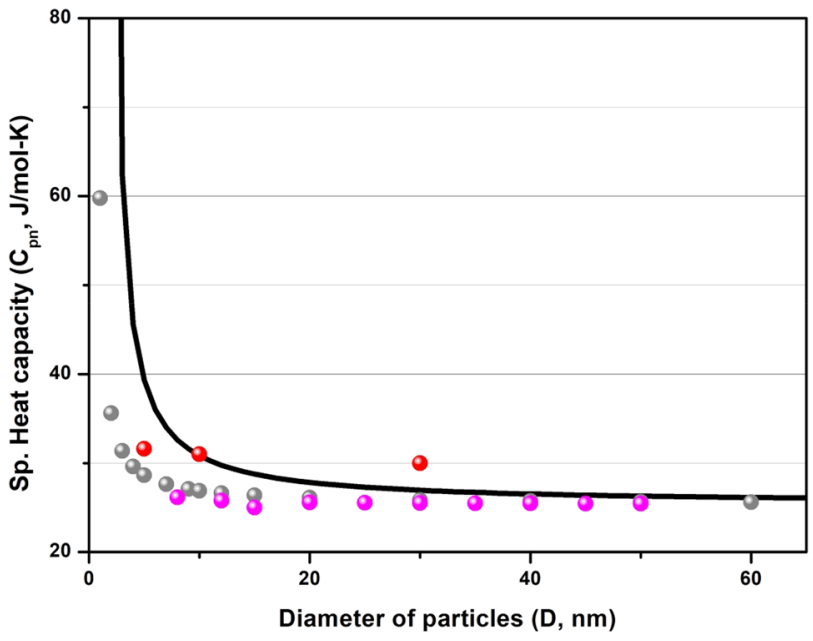

Fig. 6 Dependence of specific heat capacity on the size of spherical $\mathrm{Ag}$ nanoparticles in terms of Eq. (42). The grey sphere represents the results of the model reported by Xiong et al. (2011) [14], red and pink sphere represent experimental data and simulation results at $1000 \mathrm{~K}$ and $600 \mathrm{~K}$, respectively [70]. Input parameters for Ag nanoparticles are given in Tables 1 and 2 is the large atomic thermal vibration energies of the surface atoms. Further, it is also reported by Sun [11, 23, 72-74] that the vibrational amplitude of the surface atoms is larger for nanosolids than that of bulk materials, resulting in the higher vibrational energy of the surface atoms.

\section{Conclusions}

i. Many theoretical models based on either one-phase or two-phase proposed and predicted that the sizedependent melting temperature is linearly related. The one-phase models fail to account for the discontinuous, first-order character of the melting transition, as we do not know anything about solid to liquid states because it involves characteristics of only one of the two phases coexisting at melting, i.e. the solid-phase alone, with no separate description of the liquidphase. However, two-phase models consider both phases, solid as well as the liquid phases.

ii. The present model's prediction is based on the modified Gibbs-Thomson equation which is again a twophase type prediction. This model has been further extended to obtain the other size-dependent thermodynamic properties.

iii. It is clear from comparison of model for melting temperature, especially Qi WH [24] reported previously, the present model is based on ratio of thermodynamic energies rather ratio of number of atoms, in other words, the ratio of molar Gibbs energy to molar enthalpy $\frac{\Delta_{m} G_{m}^{\circ}}{\Delta_{m} H_{m}^{\circ}}$ is found equal to the half of the ratio of number of surface atoms to the total number of atoms $(\mathrm{N} / 2 \mathrm{n})$ in the material.

iv. The melting temperature, Debye temperature, thermal and electrical conductivity are found to decrease with the decrease in particle size, whereas the cohesive energy and specific heat capacity are increased with the decrease in particle size.

v. The output results of present model for size-dependent thermodynamic properties of metallic nanoparticles (spherical) have found in the same trends with previous models and experimental results.

vi. The consistency of the new model equation is also proving an old ambiguous and contradictory question that the high surface area of nanomaterials is responsible for the difference in most properties as compared to the bulk phase rather high curvature of their interface (due to Kelvin).

vii. The current model has the potential to be applied for various size-dependent thermodynamic properties of nanophase materials. 


\section{Appendix A}

Table 1 Bulk thermodynamic properties used in the models

\begin{tabular}{|c|c|c|c|c|c|c|}
\hline Element & $\begin{array}{l}\text { Melting tempera- } \\
\text { ture }(\mathrm{K}) \\
{[12]}\end{array}$ & $\begin{array}{l}\text { Cohesive energy } \\
(\mathrm{kJ} / \mathrm{mol}) \\
{[49]}\end{array}$ & $\begin{array}{l}\text { Debye tempera- } \\
\text { ture }(\mathrm{K}) \\
{[58,60,75]}\end{array}$ & $\begin{array}{l}\text { Thermal con- } \\
\text { ductivity } \\
(\mathrm{W} / \mathrm{m}-\mathrm{K})[76 \text {, } \\
77]\end{array}$ & $\begin{array}{l}\text { Electrical conductivity } \\
(\Omega-\mathrm{m})^{-1}[78]\end{array}$ & $\begin{array}{l}\text { Sp. heat capacity } \\
(\mathrm{J} / \mathrm{mol}-\mathrm{K})[79]\end{array}$ \\
\hline $\mathrm{Al}$ & 933.25 & - & - & - & - & - \\
\hline $\mathrm{Sn}$ & 505.06 & - & 140 & - & - & - \\
\hline $\mathrm{Pb}$ & 600 & - & - & - & - & - \\
\hline $\mathrm{Ag}$ & 1234 & - & - & 175 & - & 25.35 \\
\hline Mo & - & -598 & - & - & - & - \\
\hline W & - & -824 & - & - & - & - \\
\hline Co & - & - & 400 & - & - & - \\
\hline $\mathrm{Au}$ & - & - & 184.59 & - & - & - \\
\hline $\mathrm{Cu}$ & - & - & - & - & $9.8318 * 10^{6}$ & - \\
\hline
\end{tabular}

Table 2 Input parameters used in the models

\begin{tabular}{lllll}
\hline Element & $\begin{array}{l}\text { Molar volume } \\
\left(\mathrm{V}_{\mathrm{m}}, \mathrm{cm}^{3} / \mathrm{mol}\right) \\
{[12]}\end{array}$ & $\begin{array}{l}\text { Surface tension }\left(\gamma_{\mathrm{lg}},\right. \\
\left.J / \mathrm{m}^{2}\right)[80,81]\end{array}$ & $\begin{array}{l}\text { Surface energy }\left(\gamma_{\mathrm{sg}},\right. \\
\left.\mathrm{J} / \mathrm{m}^{2}\right)[80]\end{array}$ & $\begin{array}{l}\text { Enthalpy of fusion } \\
\left(\Delta_{m} H_{m}^{\circ}, \mathrm{kJ} / \text { mole }\right. \\
{[82]}\end{array}$ \\
\hline $\mathrm{Al}$ & 10.0 & 0.86 & 1.143 & 10.67 \\
$\mathrm{Sn}$ & 16.29 & 0.565 & 0.709 & 6.25 \\
$\mathrm{~Pb}$ & 18.26 & 0.48 & 0.593 & 5.121 \\
$\mathrm{Ag}$ & 10.27 & 0.92 & 1.246 & 11.3 \\
$\mathrm{Mo}$ & 9.38 & 2.25 & 3.0 & 27.6 \\
$\mathrm{~W}$ & 9.47 & 2.5 & 3.675 & 35.2 \\
$\mathrm{Co}$ & 6.67 & 1.928 & 2.522 & 15.2 \\
$\mathrm{Au}$ & 10.21 & 1.13 & 1.5 & 12.7 \\
$\mathrm{Cu}$ & 7.11 & 1.35 & 1.79 & 13 \\
\hline
\end{tabular}

Acknowledgements The author is thankful to the Department of Materials Science and Engineering, University of Miskolc, Hungary for valuable scientific and technical assistance.

Funding Open access funding provided by University of Miskolc.

\section{Declaration}

Data Availability Statement The data that support the findings of this study are available from the corresponding author upon reasonable request.

Open Access This article is licensed under a Creative Commons Attribution 4.0 International License, which permits use, sharing, adaptation, distribution and reproduction in any medium or format, as long as you give appropriate credit to the original author(s) and the source, provide a link to the Creative Commons licence, and indicate if changes were made. The images or other third party material in this article are included in the article's Creative Commons licence, unless indicated otherwise in a credit line to the material. If material is not included in the article's Creative Commons licence and your intended use is not permitted by statutory regulation or exceeds the permitted use, you will need to obtain permission directly from the copyright holder. To view a copy of this licence, visit http://creativecommons.org/licenses/by/4.0/.

\section{References}

1. M. Salavati-Niasari, Z. Fereshteh, F. Davar, Synthesis of oleylamine capped copper nanocrystals via thermal reduction of a new precursor. Polyhedron 28(1), 126-130 (2009)

2. F. Tavakoli, M. Salavati-Niasari, F. Mohandes, Green synthesis and characterization of graphene nanosheets. Mater. Res. Bull. 63, 51-57 (2015)

3. A. Abbasi, D. Ghanbari, M. Salavati-Niasari, M. Hamadanian, Photo-degradation of methylene blue: photocatalyst and magnetic investigation of $\mathrm{Fe} 2 \mathrm{O} 3-\mathrm{TiO} 2$ nanoparticles and nanocomposites. J. Mater. Sci.: Mater. Electron. 27(5), 4800-4809 (2016)

4. S. Mortazavi-Derazkola, M. Salavati-Niasari, O. Amiri, A. Abbasi, Fabrication and characterization of Fe3O4@SiO2@ TiO2@Ho nanostructures as a novel and highly efficient photocatalyst for degradation of organic pollution. J. Energy Chem. 26(1), 17-23 (2017) 
5. F. Ansari, A. Sobhani, M. Salavati-Niasari, Simple sol-gel synthesis and characterization of new $\mathrm{CoTiO} 3 / \mathrm{CoFe} 2 \mathrm{O} 4$ nanocomposite by using liquid glucose, maltose and starch as fuel, capping and reducing agents. J. Colloid Interface Sci. 514, 723-732 (2018)

6. S. Zinatloo-Ajabshir, M. Salavati-Niasari, Z. Zinatloo-Ajabshir, $\mathrm{Nd} 2 \mathrm{Zr} 2 \mathrm{O} 7-\mathrm{Nd} 2 \mathrm{O} 3$ nanocomposites: new facile synthesis, characterization and investigation of photocatalytic behaviour. Mater. Lett. 180, 27-30 (2016)

7. D. Ghanbari, M. Salavati-Niasari, Synthesis of urchin-like CdS$\mathrm{Fe} 3 \mathrm{O} 4$ nanocomposite and its application in flame retardancy of magnetic cellulose acetate. J. Ind. Eng. Chem. 24, 284-292 (2015)

8. M.A. Ansari, N. Jahan, Structural and Optical Properties of BaO Nanoparticles Synthesized by Facile Co-precipitation Method. Materials Highlights 2(1-2), 23-28 (2021)

9. T. Gholami, M. Salavati-Niasari, S. Varshoy, Investigation of the electrochemical hydrogen storage and photocatalytic properties of $\mathrm{CoA} 12 \mathrm{O} 4$ pigment: Green synthesis and characterization. Int. J. Hydrogen Energy 41(22), 9418-9426 (2016)

10. G. Kaptay, On the size and shape dependence of the solubility of nano-particles in solutions. Int. J. Pharm. 430(1-2), 253-257 (2012)

11. C.Q. Sun, Y. Wang, B.K. Tay, S. Li, H. Huang, Y.B. Zhang, Correlation between the melting point of a nanosolid and the cohesive energy of a surface atom. J. Phys. Chem. B 106(41), 10701-10705 (2002)

12. K.K. Nanda, S.N. Sahu, S.N. Behera, Liquid-drop model for the size-dependent melting of low-dimensional systems. Phys. Rev. A 66(1), 013208 (2002)

13. M.A. Shandiz, Effective coordination number model for the size dependency of physical properties of nanocrystals. J. Phys.: Condens. Matter 20(32), 325237 (2008)

14. S. Xiong, W. Qi, Y. Cheng, B. Huang, M. Wang, Y. Li, Universal relation for size dependent thermodynamic properties of metallic nanoparticles. Phys. Chem. Chem. Phys. 13(22), 10652-10660 (2011)

15. G.K. Straub, J.B. Aidun, J.M. Wills, C.R. Sanchez-Castro, D.C. Wallace, $\mathrm{Ab}$ initio calculation of melting and thermodynamic properties of crystal and liquid aluminum. Phys. Rev. B 50(8), 5055 (1994)

16. J.S. Tse, D.D. Klug, K. Uehara, Z.Q. Li, J. Haines, J.M. Léger, Elastic properties of potential superhard phases of RuO 2. Phys. Rev. B 61(15), 10029 (2000)

17. Sutherland, W. (1891). V. A kinetic theory of solids, with an Experimental Introduction. The London, Edinburgh and Dublin Philosophical Magazine and Journal of Science. 32(194), 31-43.

18. F.A. Lindemann, The calculation of molecular vibration frequency. Z. phys 11, 609-612 (1910)

19. M. Wautelet, Estimation of the variation of the melting temperature with the size of small particles, on the basis of a surface-phonon instability model. J. Phys. D Appl. Phys. 24(3), 343 (1991)

20. Q. Jiang, Z. Zhang, J.C. Li, Melting thermodynamics of nanocrystals embedded in a matrix. Acta Mater. 48(20), 4791-4795 (2000)

21. L. Burakovsky, D.L. Preston, Analysis of dislocation mechanism for melting of elements. Solid State Commun. 115(7), 341-345 (2000)

22. L. Burakovsky, D.L. Preston, R.R. Silbar, Melting as a dislocation-mediated phase transition. Phys. Rev. B 61(22), 15011 (2000)

23. C.Q. Sun, B.K. Tay, X.T. Zeng, S. Li, T.P. Chen, J.I. Zhou, E.Y. Jiang, Bond-order-bond-length-bond-strength (bond-OLS) correlation mechanism for the shape-and-size dependence of a nanosolid. J. Phys.: Condens. Matter 14(34), 7781 (2002)

24. W.H. Qi, Size effect on melting temperature of nanosolids. Physica B 368(1-4), 46-50 (2005)

25. W.H. Qi, M.P. Wang, Size and shape dependent melting temperature of metallic nanoparticles. Mater. Chem. Phys. 88(2-3), 280-284 (2004)
26. A. Safaei, M.A. Shandiz, S. Sanjabi, Z.H. Barber, Modelling the size effect on the melting temperature of nanoparticles, nanowires and nanofilms. J. Phys.: Condens. Matter 19(21), 216216 (2007)

27. A. Safaei, M.A. Shandiz, S. Sanjabi, Z.H. Barber, Modeling the melting temperature of nanoparticles by an analytical approach. The Journal of Physical Chemistry C 112(1), 99-105 (2008)

28. A.V. Granato, D.M. Joncich, V.A. Khonik, Melting, thermal expansion and the Lindemann rule for elemental substances. Appl. Phys. Lett. 97(17), 171911 (2010)

29. C.A. Johnson, Generalization of the Gibbs-Thomson equation. Surf. Sci. 3(5), 429-444 (1965)

30. E. Roduner, Size-dependent chemistry: Properties of nanocrystals. Chem Soc Rev 35(583), 10-1039 (2006)

31. K.J. Hanszen, Theoretische untersuchungen über den schmelzpunkt kleiner kügelchen. Z. Phys. 157(5), 523-553 (1960)

32. P. Pawlow, The dependency of the melting point on the surface energy of a solid body. Z. phys. Chem 65(5), 545-548 (1909)

33. P.R. Couchman, W.A. Jesser, Thermodynamic theory of size dependence of melting temperature in metals. Nature 269(5628), 481-483 (1977)

34. G. Guisbiers, M. Wautelet, Size, shape and stress effects on the melting temperature of nano-polyhedral grains on a substrate. Nanotechnology 17(8), 2008 (2006)

35. H.M. Lu, F.Q. Han, X.K. Meng, Size-dependent thermodynamic properties of metallic nanowires. J. Phys. Chem. B 112(31), 9444 $9448(2008)$

36. H.M. Lu, P.Y. Li, Z.H. Cao, X.K. Meng, Size-, shape- and dimensionality-dependent melting temperatures of nanocrystals. The Journal of Physical Chemistry C 113(18), 7598-7602 (2009)

37. G. Guisbiers, Review on the analytical models describing melting at the nanoscale. J. Nanosci. Lett 2(8), 1-10 (2012)

38. G. Kaptay, The Gibbs equation versus the Kelvin and the GibbsThomson equations to describe nucleation and equilibrium of nano-materials. J. Nanosci. Nanotechnol. 12(3), 2625-2633 (2012)

39. G. Kaptay, On the size dependence of molar and specific properties of independent nano-phases and those in contact with other phases. J. Mater. Eng. Perform. 27(10), 5023-5029 (2018)

40. T.B. David, Y. Lereah, G. Deutscher, R. Kofman, P. Cheyssac, Solid-liquid transition in ultra-fine lead particles. Philos. Mag. A 71(5), 1135-1143 (1995)

41. S. Xiao, W. Hu, J. Yang, Melting temperature: From nanocrystalline to amorphous phase. J. Chem. Phys. 125(18), 184504 (2006)

42. P. Puri, V. Yang, Effect of particle size on melting of aluminum at nano scales. The Journal of Physical Chemistry C 111(32), 11776-11783 (2007)

43. K.K. Nanda, Size-dependent melting of nanoparticles: Hundred years of thermodynamic model. Pramana 72(4), 617-628 (2009)

44. L. Gråbaek, J. Bohr, E. Johnson, A. Johansen, L. Sarholt-Kristensen, H.H. Andersen, Superheating and supercooling of lead precipitates in aluminum. Phys. Rev. Lett. 64(8), 934 (1990)

45. J. Zhong, L.H. Zhang, Z.H. Jin, M.L. Sui, K. Lu, Superheating of Ag nanoparticles embedded in Ni matrix. Acta Mater. 49(15), 2897-2904 (2001)

46. F.G. Shi, Size dependent thermal vibrations and melting in nanocrystals. J. Mater. Res. 9(5), 1307-1314 (1994)

47. Skripov, V. P., Koverda, V. P., \& Skokov, V. N. (1981). Size effect on melting of small particles. physica status solidi (a), 66(1), $109-118$.

48. J. Eckert, J.C. Holzer, C.C. Ahn, Z. Fu, W.L. Johnson, Melting behavior of nanocrystalline aluminum powders. Nanostruct. Mater. 2(4), 407-413 (1993)

49. Kaptay, G., Csicsovszki, G., \& Yaghmaee, M. S. (2003). An absolute scale for the cohesion energy of pure metals. In Materials Science Forum (Vol. 414, pp. 235-240). Trans Tech Publications Ltd. 
50. H.K. Kim, S.H. Huh, J.W. Park, J.W. Jeong, G.H. Lee, The cluster size dependence of thermal stabilities of both molybdenum and tungsten nanoclusters. Chem. Phys. Lett. 354(1-2), 165-172 (2002)

51. W.H. Qi, M.P. Wang, G.Y. Xu, The particle size dependence of cohesive energy of metallic nanoparticles. Chem. Phys. Lett. 372(5-6), 632-634 (2003)

52. Smith, D. W. (1990). Inorganic substances: a prelude to the study of descriptive inorganic chemistry. Cambridge university press. p. 117

53. Q. Chen, B. Sundman, Calculation of Debye temperature for crystalline structures-a case study on $\mathrm{Ti}, \mathrm{Zr}$ and Hf. Acta Mater. 49(6), 947-961 (2001)

54. C. Kittel, Introduction to Solid State Physics (John Wiley \& Sons. Inc., New York, 2004).

55. S. Xiong, W. Qi, B. Huang, M. Wang, Y. Li, Size and shape dependent Gibbs free energy and phase stability of titanium and zirconium nanoparticles. Mater. Chem. Phys. 120(2-3), 446-451 (2010)

56. J.G. Dash, History of the search for continuous melting. Rev. Mod. Phys. 71(5), 1737 (1999)

57. L.H. Liang, B. Li, Size-dependent thermal conductivity of nanoscale semiconducting systems. Phys. Rev. B 73(15), 153303 (2006)

58. M. Hou, M. El Azzaoui, H. Pattyn, J. Verheyden, G. Koops, G. Zhang, Growth and lattice dynamics of Co nanoparticles embedded in Ag: a combined molecular-dynamics simulation and Mössbauer study. Phys. Rev. B 62(8), 5117 (2000)

59. A. Balerna, S. Mobilio, Dynamic properties and Debye temperatures of bulk $\mathrm{Au}$ and Au clusters studied using extended x-rayabsorption fine-structure spectroscopy. Phys. Rev. B 34(4), 2293 (1986)

60. G.E.J. Koops, H. Pattyn, A. Vantomme, S. Nauwelaerts, R. Venegas, Extreme lowering of the Debye temperature of Sn nanoclusters embedded in thermally grown $\mathrm{Si} \mathrm{O} 2$ by low-lying vibrational surface modes. Phys. Rev. B 70(23), 235410 (2004)

61. J.M. Zimann, Electrons and Phonons, Clarendon Press, Oxford,1960, pp. 288, 58, 296, 456.

62. A.R. Regel, V.M. Glazov, Entropy of melting of semiconductors. Semiconductors 29(5), 405-417 (1995)

63. P. Warrier, A. Teja, Effect of particle size on the thermal conductivity of nanofluids containing metallic nanoparticles. Nanoscale Res. Lett. 6(1), 1-6 (2011)

64. R. Franz, G. Wiedemann, Ueber die Wärme-Leitungsfähigkeit der Metalle. Ann. Phys. 165(8), 497-531 (1853)

65. Jones, W., \& March, N. H. (1985). Theoretical solid state physics (Vol. 35). Courier Corporation.

66. Yuliza, E., Murniati, R., Rajak, A., \& Abdullah, M. (2015, January). Effect of Particle Size on the Electrical Conductivity of
Metallic Particles. In 2014 International Conference on Advances in Education Technology (ICAET-14). Atlantis Press.

67. P. Nath, K.L. Chopra, Thermal conductivity of copper films. Thin Solid Films 20(1), 53-62 (1974)

68. Ziman, J.M. (1976). Principles of Theory of Solids. Cambridge University Press, Cambridge, 2nd ed.

69. Y.F. Zhu, J.S. Lian, Q. Jiang, Modeling of the melting point, Debye temperature, thermal expansion coefficient and the specific heat of nanostructured materials. The Journal of Physical Chemistry C 113(39), 16896-16900 (2009)

70. W. Luo, W. Hu, S. Xiao, Size effect on the thermodynamic properties of silver nanoparticles. The Journal of Physical Chemistry C 112(7), 2359-2369 (2008)

71. J. Rupp, R. Birringer, Enhanced specific-heat-capacity (c p) measurements (150-300 K) of nanometer-sized crystalline materials. Phys. Rev. B 36(15), 7888 (1987)

72. C.Q. Sun, Y. Shi, C.M. Li, S. Li, T.A. Yeung, Size-induced undercooling and overheating in phase transitions in bare and embedded clusters. Phys. Rev. B 73(7), 075408 (2006)

73. M. Wautelet, On the melting of polyhedral elemental nanosolids. The European Physical Journal-Applied Physics 29(1), 51-54 (2005)

74. C.Q. Sun, Size dependence of nanostructures: Impact of bond order deficiency. Prog. Solid State Chem. 35(1), 1-159 (2007)

75. C.C. Yang, M.X. Xiao, W. Li, Q. Jiang, Size effects on Debye temperature, Einstein temperature and volume thermal expansion coefficient of nanocrystals. Solid State Commun. 139(4), 148-152 (2006)

76. Ho, C. Y., Powell, R. W., \& Liley, P. E. (1974). Thermal conductivity of the elements: a comprehensive review. p. I-243

77. Yaws, C. L. (2015). The yaws handbook of physical properties for hydrocarbons and chemicals: physical properties for more than 54,000 organic and inorganic chemical compounds, Coverage for $\mathrm{C} 1$ to $\mathrm{C} 100$ Organics and Ac to Zr Inorganics. Gulf Professional Publishing. p. 455

78. Matula, R. A. (1979). Electrical resistivity of copper, gold, palladium and silver. Journal of Physical and Chemical Reference Data, 8(4), 1147-1298. p. 1161

79. D.R. Lide, CRC Handbook of Chemistry and Physics, 88th edn. (Florida, Taylor \& Francis Group, 2008), pp. 4-135

80. L. Vitos, A.V. Ruban, H.L. Skriver, J. Kollar, The surface energy of metals. Surf. Sci. 411(1-2), 186-202 (1998)

81. B.J. Keene, Review of data for the surface tension of pure metals. Int. Mater. Rev. 38(4), 157-192 (1993)

82. M. de Podesta, Understanding the Properties of Matter, 2nd edn. (CRC Press, London, 2002), p. 355

Publisher's Note Springer Nature remains neutral with regard to jurisdictional claims in published maps and institutional affiliations. 